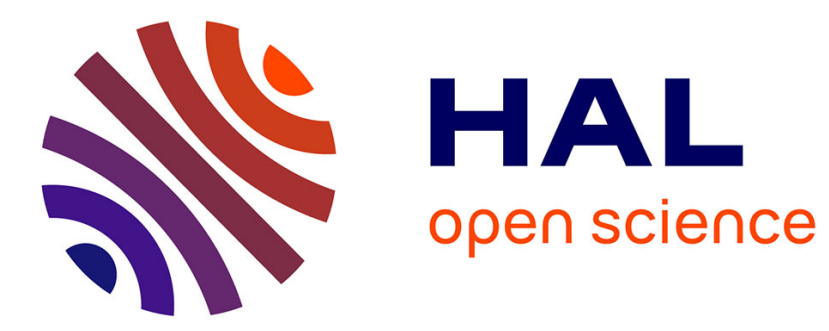

\title{
Does demand noise matter? Identification and implications
}

Kenza Benhima, Céline Poilly

\section{To cite this version:}

Kenza Benhima, Céline Poilly. Does demand noise matter? Identification and implications. Journal of Monetary Economics, 2021, 117, pp.278-295. 10.1016/j.jmoneco.2020.01.006 . hal-03173423

\section{HAL Id: hal-03173423 \\ https://hal-amu.archives-ouvertes.fr/hal-03173423}

Submitted on 29 Jan 2022

HAL is a multi-disciplinary open access archive for the deposit and dissemination of scientific research documents, whether they are published or not. The documents may come from teaching and research institutions in France or abroad, or from public or private research centers.
L'archive ouverte pluridisciplinaire $\mathbf{H A L}$, est destinée au dépôt et à la diffusion de documents scientifiques de niveau recherche, publiés ou non, émanant des établissements d'enseignement et de recherche français ou étrangers, des laboratoires publics ou privés.

\section{(이)(\$)}

Distributed under a Creative Commons Attribution - NonCommercial - NoDerivatives| 4.0 


\title{
Does demand noise matter? Identification and implications
}

\author{
Kenza Benhima a, Céline Poilly b, * \\ a University of Lausanne, HEC-Lausanne and CEPR, UNIL-Dorigny, Lausanne 1015, Switzerland \\ ${ }^{\mathrm{b}}$ Aix-Marseille University, CNRS, EHESS, Centrale Marseille, IRD, AMSE, Marseille, France
}

\begin{abstract}
A B S T R A C T
We assess the role of demand noise (excessive optimism or pessimism about demand) to- gether with supply noise (excessive optimism or pessimism about supply). To do so, we propose a methodology to decompose business cycles into supply, demand, supply noise and demand noise shocks, using a structural vector autoregression model. Key to our iden- tification of both supply noise and demand noise is the use of sign restrictions on survey expectation errors about output growth and about inflation. We show that demand-related noise shocks have a negative effect on output and contribute substantially to its fluctua- tions. Monetary policy and private information seem to play a key role in the transmission of demand noise shocks.
\end{abstract}

Keywords: Business cycle, Information friction, Noise shock, SVAR with sign restriction

JEL classification: E32 D82 C32 E31

\section{Introduction}

It is commonly accepted that expectations on economic activity can be important drivers of fluctuations by generating waves of optimism and pessimism. This idea, which dates back to Pigou (1926) and Keynes (1936), has been revived recently through the concepts of "news", "animal spirits" or "sentiments". ${ }^{2}$ Agents are imperfectly informed about what is going on in the economy and have "misperceptions" about the state of fundamentals. The recent literature has been mostly focused on misperceptions of total factor productivity (TFP). These misperceptions have been rationalized by noise shocks affecting a common signal about TFP. Several authors argue that these supply-related noise shocks resemble demand shocks and account for a significant share of short-term and medium-term output fluctuations. ${ }^{3}$ However, demand-related noise shocks, that is, noise that would affect a common signal on demand shocks, have been largely neglected.

This paper is the first attempt to assess the effect of demand noise and it shows that its impact is recessionary and substantial. We propose a methodology to decompose business cycles into supply, demand, supply noise and demand noise shocks, using a structural vector autoregression (SVAR) model. Key to our identification of both supply noise and demand

\footnotetext{
* Corresponding author.

E-mail addresses: kenza.benhima@unil.ch (K. Benhima), celine.poilly@univ-amu.fr (C. Poilly).

2 See, for instance, Beaudry and Portier (2004), Jaimovich and Rebelo (0000) and Barsky and Sims (2012) for the "news" approach, Lorenzoni (2009) for the “noise" approach and Angeletos and La'o (2013) and Benhabib et al. (2015) for the "sentiments" approach. Melosi (2014) and Milani (2017) also analyze nearrational agents models.

3 See Lorenzoni (2009), Blanchard et al. (2013), Forni et al. (2017), Zeno et al. (2018), Dees and Zimic (2019) and Chahrour and Ulbricht (2019). Other papers find a lower contribution of noise shocks, such as Barsky and Sims (2012), Angeletos and La'o (2013) and Fève and Guay (2019)
} 


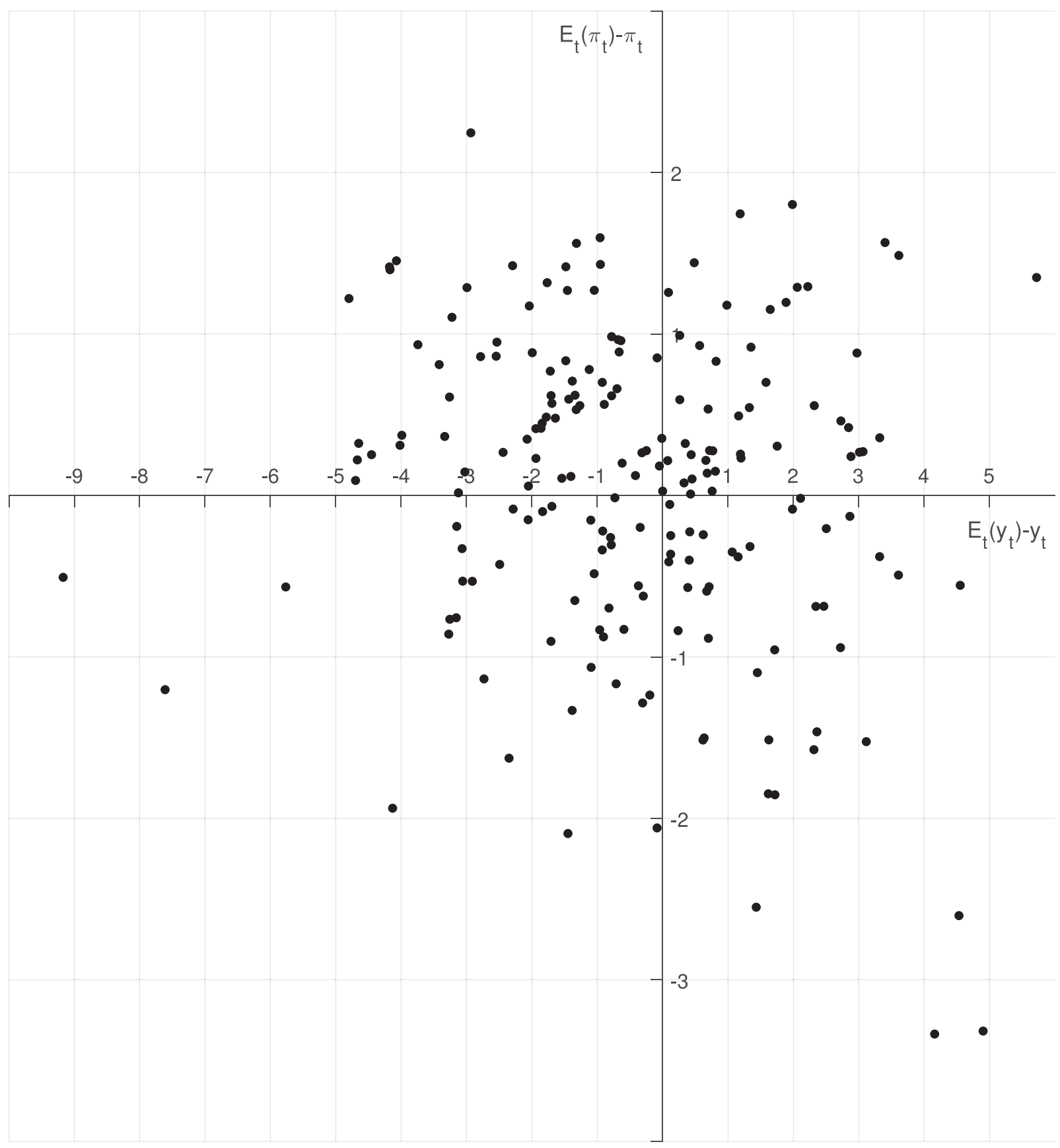

Fig. 1. GDP growth and inflation: Nowcast errors (in p.p). Note: Nowcast error of real GDP growth and GDP deflator inflation in percentage point over 1968q1-2017q1. Nowcast errors of real GDP growth ( $\mathrm{x}$ axis) is computed as the difference between the nowcast prediction and the realized value of of the annualized real GDP growth rate. The nowcast error on inflation is computed as the difference between the nowcast prediction and the realized value of the annualized GDP deflator inflation rate. The nowcast data are from the SPF of the Fed of Philadelphia.

noise is the use of sign restrictions on survey expectation errors about output growth and about inflation. Indeed, the literature so far has exploited one type of expectation error (typically, on output growth) to identify one type of noise (typically, supply noise), but to disentangle two types of noise, we need more information. Intuitively, if survey expectations overestimate output growth, this can reflect excessive optimism either about the state of supply or about the state of demand. However, if they are overoptimistic about demand, then, assuming that demand shocks are inflationary, they should overestimate inflation as well. In contrast, if they are overoptimistic about supply, they should underestimate inflation, assuming that supply shocks are deflationary. To illustrate this point, Fig. 1 shows nowcast errors about US real GDP growth and inflation 
over 1968q1-2017q1. ${ }^{4}$ Nowcast errors are the difference between the nowcast prediction of a variable and its realization. In the figure, nowcast errors about output sometimes have the same sign as the nowcast errors about inflation, and sometimes they do not. This suggests that errors about both supply and demand are necessary to explain the data.

Using a reduced-form model that incorporates both decision makers (firms and households) and survey participants who produce nowcasts ("nowcasters"), we show that for the survey expectation errors to capture economically relevant noise shocks, all it takes is that nowcasters' expectations are driven by the same aggregate noise as the decision makers in the economy and that the presence of private information among decision makers. Indeed, if all information were public, then there would be no expectation errors, as nowcasters would share the same - although possibly noisy - information with decision makers. This rationalizes the now common use of professionals' expectations in the literature to uncover noise shocks. ${ }^{5}$ Particularly relevant for our approach, we show in the reduced-form model that the errors made by rational nowcasters should be internally consistent: If demand (supply) shocks drive a positive (negative) correlation between output and inflation, they should drive a positive (negative) correlation between the errors about output and about inflation.

In relation to that, we point out that private information also matters in the typical non-invertibility problem (the inability to recover shocks from observables) that econometricians face when they use SVAR models to identify noise shocks (Blanchard et al., 2013). First and foremost, in our setup, the econometrician has access to more information than nowcasters to recover fundamental and noise shocks as she uses the actual realization of variables while nowcasters cannot. Second, we assume that some agents have private information about the fundamental shocks, which is particularly relevant since we are considering contemporaneous shocks. In particular, it is natural to assume that the supply side of the economy observes and reacts to supply shocks and that the demand side observes and reacts to demand shocks. The resulting output and inflation are then linearly independent of their survey expectations, which ensures invertibility. Therefore, having sufficient information on one side of the economy does not prevent noise shocks from generating interesting dynamics, because the other side of the economy is still uninformed, but it helps to solve the non-invertibility issue.

Our SVAR model, estimated on the basis of US data over the sample 1969q1-2017q1, includes real GDP growth, the inflation rate and their corresponding nowcast errors. We follow Blanchard and Quah (1989) and identify fundamental supply shocks by restricting all other shocks to have no long-run effect on real GDP. Therefore, demand shocks as well as supply noise and demand noise shocks are all transitory shocks. After restricting the signs of the impact responses of nowcast errors to these shocks, only a limited number of sign restrictions on the responses of inflation and output are needed. We therefore assume that positive signals about supply are expansionary and that positive signals about demand are inflationary. These additional restrictions are relaxed in a robustness exercise, where we show that the results about demand noise are particularly robust.

Our main results are twofold. First, demand noise shocks explain $24 \%$ of output growth volatility, while supply noise shocks explain only $8 \%$. Imperfect information on demand has thus deeper consequences on economic activity than imperfect information on supply. Second, we find that demand noise shocks are recessionary. Since we restrict these shocks to be inflationary, this means that they look like supply shocks. This echoes the findings by Lorenzoni (2009) who emphasizes that supply noise shocks (overestimating TFP) are observationally equivalent to fundamental demand shocks. We extend his results by showing that some shocks that resemble supply shocks have actually to do with imperfect information on the demand side.

Our set of restrictions can be rationalized through a noisy-information extension of a simple New Keynesian model with both supply (technology) and demand (preference) shocks. Nowcasters publish nowcasts, and a central bank sets the nominal interest rate. Households know their preferences, and firms know technology, otherwise the agents' information is made up of public signals (that are hit by noise shocks) and private signals about demand and supply shocks. Closed-form solutions of a limit case and simulations of an extended version of the model across a wide range of parameters point toward the validity of our restrictions.

We then use the model to estimate the information-related parameters and dissect the mechanism. This helps to understand under which conditions the contribution of demand noise shocks to output is large and the transmission channel of these shocks. Our results are twofold. First, we stress that the effect of demand noise shocks on output originates in a "monetary policy channel" : As the central bank receives a positive signal about demand, it expects a rise in inflation and increases the interest rate accordingly. This rise in interest rate then depresses aggregate demand, leading to recessionary demand noise shocks, as observed in the data. The strength of the monetary policy channel affects the magnitude of the output response to demand noise shocks. More precisely, when demand shocks are persistent, the effect of demand noise shocks on output is amplified, as households anticipate a persistent rise in interest rate. In this context, a monetary policy rule that reacts strongly to inflation mitigates the impact of demand noise. Indeed, in that case, firms that anticipate a stronger policy response increase prices less, which leads to a milder increase in the interest rate and thus to a milder recession. This is consistent with the data, as we do observe an increase in interest rate in our sample following a demand

\footnotetext{
4 The realization of real GDP growth expressed in annualized rate is extracted from the Bureau of Economic Analysis, and the realization of annualized inflation rate is from the Bureau of Labor Statistics. Nowcasts are provided by the Survey of Professional Forecasters (SPF) of the Federal Reserve Bank of Philadelphia.

${ }^{5}$ Indeed, quantitative assessments of economic variables by professional forecasters are more commonly available than assessments by firms or consumers, which are mostly qualitative. See, for instance, the Philadelphia Federal Reserve Bank's Manufacturing Business Outlook Survey or the University of Michigan's Surveys of Consumers.
} 
noise shock. Moreover, we observe a milder response of output, inflation and interest rate when restricting the sample to the Great Moderation period. Second, we uncover what we call a "firms' information paradox". It is a well-understood fact that if we shut down households' private information on supply shocks, the effect of supply noise shocks on output is larger. On the opposite, when we shut down firms' private information on demand shocks, the effect of demand noise shocks on output is milder. This in fact results from a more responsive inflation. Indeed, when firms are less able to distinguish noise shocks from fundamental demand shocks, they tend to increase their prices more when receiving a positive public signal, making the noise shock more inflationary. Higher inflation mitigates the increase in the real interest rate, thus generating a milder recession.

We contribute to the literature that seeks to identify information frictions. Chahrour and Ulbricht (2019) capture information rigidities through the "wedges" in agents' expectations and show that households are imperfectly informed about technology. Our additional finding is that firms also have imperfect information about demand shocks. This is consistent with the empirical evidence of Coibion et al. (2018), who find a large amount of disagreement about aggregate inflation among firms. Coibion and Gorodnichenko (2012), Coibion and Gorodnichenko (2015) and Andrade et al. (2016) use survey forecast data to assess the extent of information frictions among nowcasters. Our paper is also related to studies of the effect of expectations about demand on economic fluctuations. Fiscal and monetary news, in particular, have been the focus of attention (see, for instance, Leeper et al., 2013). Most of the studies focus on foresighted versus unexpected demand shocks, not demand noise. To the best of our knowledge, we are the first to quantify the contribution to business cycles of noise shocks on demand and to stress their recessionary effect. ${ }^{6}$

The paper is structured as follows. Section 2 explains the principles behind our identification strategy. Section 3 describes the SVAR estimation strategy and our empirical results. Section 4 sets out a New Keynesian model with imperfect information, which we use to rationalize our sign restrictions and to interpret our results. Section 5 concludes.

\section{Identifying noise shocks using sign restrictions}

In this section, we explain how multiple noise shocks can be identified using sign restrictions on survey nowcast errors. Key to our methodology are the presence of variables whose conditional correlations differ across the corresponding fundamental shocks and the availability of survey expectations about these variables. We then use the fact that, if nowcasters are rational, their expectation errors should be consistent. Since demand shocks drive a positive correlation between output and inflation, we expect error shocks about demand to drive a positive correlation between the errors about output and inflation. We illustrate this point using a reduced-form model of consumption and price setting, focusing on demand shocks and noise about demand, where we introduce a representative nowcaster. One important issue is: How can we capture the noise that drives economic decisions through nowcasters' expectations that are not direct measures of the decision makers' expectations? ${ }^{7}$ We show that to be able to exploit survey expectation errors, we need that nowcasters observe the same public noisy signals as the agents and the presence of private information among decision makers. We also discuss how the non-invertibility issue that typically arises when trying to identify noise shocks is circumvented in this setup.

\subsection{A reduced-form model with demand shocks and imperfect information}

Consider an economy with a continuum [0,1] of firms and a representative household. The household's consumption follows $c_{t}=\epsilon_{t}$, where $\epsilon_{t} \sim \mathcal{N}\left(0, \sigma^{2}\right)$ is a fundamental demand shock. As we show in Section 4, this shock can be rationalized as a preference shock that shifts the time preference rate of the households. Assuming that consumption is the only driver of aggregate demand, we have $y_{t}=c_{t}$, where $y_{t}$ is equilibrium output. This yields

$$
y_{t}=\epsilon_{t}
$$

Firm $i \in[0,1]$ sets its price to satisfy $p_{i t}=\kappa E_{i t}^{f}\left(y_{t}\right)=\kappa E_{i t}^{f}\left(\epsilon_{t}\right)$, where $E_{i t}^{f}($.$) denotes the rational expectation of firm i$, given its information in $t$, and $\kappa>0$ is the optimal response of individual prices to firms' expectations of $\epsilon_{t}$. This equation can be rationalized by the fact that prices are predetermined, that aggregate demand pushes up the demand for individual goods, and that to serve the demand for their good, firms will have to face higher marginal costs. The aggregate price $p_{t}=\int_{0}^{1} p_{i t} d i$ can then be written as

$$
p_{t}=\kappa \bar{E}_{t}^{f}\left(\epsilon_{t}\right)
$$

where $\bar{E}_{t}^{f}\left(\epsilon_{t}\right)=\int_{0}^{1} E_{i t}^{f}\left(\epsilon_{t}\right) d i$ are the average expectations of firms.

In this economy, a representative nowcaster produces expectations of the current level (nowcasts) of the aggregate price $E_{t}^{s}\left(p_{t}\right)$ and of output $E_{t}^{S}\left(y_{t}\right)$. We refer to these expectations as survey expectations even though we have only one representative nowcaster.

\footnotetext{
${ }^{6}$ Ricco (2015) identifies news and noise fiscal shocks using nowcast errors about government spending growth. Instead, we use nowcast errors about output growth and inflation to identify fundamental and noise shocks. Fève and Pietrunti (2016) measure the amount of noise in fiscal policy signaling by using survey data for several countries. They do not, however, empirically estimate the effect of noise shocks, nor do they quantify their contribution to business cycles.

7 Below, expectation errors are measured by nowcast errors emanating from the US SPF. In this survey, forecasters are largely from the research, business and financial sectors. They are anonymous, to avoid any conflict of interest with their employers' performances (Croushore, 1993).
} 
The informational structure in the model consists of public and private signals. Public signals on $\epsilon_{t}, s_{t}=\epsilon_{t}+e_{t}$, are observed throughout the economy, namely households, firms and nowcaster, where $e_{t} \sim \mathcal{N}\left(0, \sigma_{0}^{2}\right)$ denotes an aggregate noise shock and $\sigma_{0}^{-2}$ is the precision of the public signal. Firm $i \in[0,1]$ receives a private signal, $x_{i t}^{f}=\epsilon_{t}+\lambda_{i t}^{f}$, where $\lambda_{i t}^{f} \sim$ $\mathcal{N}\left(0,\left(\sigma_{1}^{f}\right)^{2}\right)$ is an idiosyncratic noise shock satisfying $\int_{0}^{1} \lambda_{i t}^{f} d i=0$ and $\left(\sigma_{1}^{f}\right)^{-2}$ is the precision of the private signal. The nowcaster observes only public signals. ${ }^{8}$

The firm's expectations are $E_{i t}^{f}\left(\epsilon_{t}\right)=\delta_{0}^{f} s_{i t}+\delta_{1}^{f} x_{i t}^{f}$, with $\delta_{0}^{f}=\sigma_{0}^{-2} /\left[\sigma^{-2}+\sigma_{0}^{-2}+\left(\sigma_{1}^{f}\right)^{-2}\right]$ and $\delta_{1}^{f}=\left(\sigma_{1}^{f}\right)^{-2} /\left[\sigma^{-2}+\sigma_{0}^{-2}+\right.$ $\left(\sigma_{1}^{f}\right)^{-2}$. Average expectations are then $\bar{E}_{t}^{f}\left(\epsilon_{t}\right)=\int_{0}^{1} E_{i t}^{f}\left(\epsilon_{t}\right) d i=\delta_{0}^{f} S_{t}+\delta_{1}^{f} \epsilon_{t}$, so that the aggregate price depends on the public signal and on the demand shock:

$$
p_{t}=\kappa \int_{0}^{1} E_{i t}^{f}\left(\epsilon_{t}\right) d i=\kappa\left(\delta_{0}^{f} s_{t}+\delta_{1}^{f} \epsilon_{t}\right)
$$

Because firms respond to their signals, prices respond positively to demand shocks $\epsilon_{t}$, but also to demand noise shocks $e_{t}$. We show in the following how survey expectation errors can help us to capture this noise shock. Before considering the nowcaster's expectation errors, notice that $\delta_{1}^{f}=0$ when firms' private information vanishes, that is, $\left(\sigma_{1}^{f}\right)^{-2}=0$. In this case, firms' expectations are driven only by the public signal. Outside this limit case, the fundamental shock contributes to firms' expectations independently of the public signal $s_{t}$. Therefore, it is possible for the nowcaster, who observes $s_{t}$, to infer perfectly the part that is due to the common signal $\delta_{0}^{f} s_{t}$, but the second part $\delta_{1}^{f} \epsilon_{t}$ remains to forecast.

\subsection{Survey expectation errors}

Using $E_{t}^{s}\left(\epsilon_{t}\right)=\delta_{0}^{s} s_{t}$, with $\delta_{0}^{s}=\sigma_{0}^{-2} /\left[\sigma^{-2}+\sigma_{0}^{-2}\right]$, and $E_{t}^{s}\left(s_{t}\right)=s_{t}$, we obtain

$$
\begin{aligned}
& E_{t}^{s}\left(y_{t}\right)-y_{t}=E_{t}^{s}\left(\epsilon_{t}\right)-\epsilon_{t} \\
& E_{t}^{s}\left(p_{t}\right)-p_{t}=\kappa \delta_{1}^{f}\left[E_{t}^{s}\left(\epsilon_{t}\right)-\epsilon_{t}\right]
\end{aligned}
$$

with $E_{t}^{s}\left(\epsilon_{t}\right)-\epsilon_{t}=-\left(1-\delta_{0}^{s}\right) \epsilon_{t}+\delta_{0}^{s} e_{t}$. Because the nowcaster forms expectations rationally, and because prices and output depend positively on $\epsilon_{t}$, the errors about output and inflation depend positively on the errors nowcasters make about $\epsilon_{t}$. More precisely, the relevant parameters are the agents' (firms, household) private response to $\epsilon_{t}$. In the case of output, this is 1 , because households are directly hit by the demand shock. In the case of prices, this is $\kappa \delta_{1}^{f}$, which is strictly positive if firms have private information. All in all, because a demand shock drives a positive private response of both inflation and prices, the shocks that drive the error about demand (fundamental demand and demand noise shocks) must generate a positive correlation of the errors. Importantly, for this implication to hold for demand noise shocks, the public signal must be in the information set of the nowcaster, so that $\delta_{0}^{S}>0$.

We extrapolate these insights as follows. To apply sign restrictions on errors, we need (1) nowcasters to share the same public signals as decision makers, (2) the decision makers to have some private information and (3) some priors on the optimal "private" response of the relevant decision makers when setting their choice variable. ${ }^{9}$ This implication is particularly relevant to disentangle different types of noise shocks. In particular, if we assume that supply shocks drive a positive private response of output and a negative private response of prices, then supply and supply noise shocks must generate a negative correlation between the errors.

Note, however, that fundamental and noise shocks cannot be distinguished from one another solely on the basis of errors. In our example, following a positive demand shock $\left(\epsilon_{t}>0\right)$, nowcasters underestimate output and prices. Following a positive noise shock $\left(e_{t}>0\right)$, they overestimate output and prices. Focusing on errors, a demand noise shock therefore looks like a negative demand shock. To distinguish demand from demand noise shocks, restrictions on errors must be complemented with restrictions on output or inflation. Here, we could use the fact that firms tend to increase prices following both demand and demand noise shocks. In the next section, we use these insights to identify noise about supply and demand using sign restrictions.

\subsection{Invertibility}

Non-invertibility is a common issue under imperfect information. Intuitively, as pointed out by Blanchard et al. (2013), if economic agents do not have enough information to distinguish fundamental shocks from noise shocks, then neither does the econometrician. Namely, the structural shocks cannot be recovered from the observables. In this situation, the VAR does not have a unique MA representation, and hence the true impulse response functions (IRFs) cannot be recovered. To rule out non-ivertibility, we use the fact that the actual realizations of output and inflation, which are not contemporaneously available to the agents, are eventually available to the econometrician. To be actually useful, i.e. to help disentangle fundamental from noise shocks, these realizations need to be linearly independent from the public signals. This is the case here as long

\footnotetext{
8 In Section 4, we endow nowcasters with private signals. Assuming no private information for nowcasters is without loss of generality.

${ }^{9}$ Note that the assumption that decision makers have private information does not necessarily mean that their information is superior to the nowcasters'. It simply means that they have access to different sources of information.
} 
as agents (firms and households) have private information. To see this, consider our reduced-form model with demand and demand noise shocks. To identify these two shocks, it should be enough to focus on two variables, provided that the system is invertible. Suppose we were trying to use output $y_{t}$ and its average expectation $E_{t}^{s}\left(y_{t}\right)$ to uncover $\epsilon_{t}$ and $e_{t}$ :

$$
\left(\begin{array}{c}
y_{t} \\
\bar{E}_{t}^{s}\left(y_{t}\right)
\end{array}\right)=\left(\begin{array}{c}
\epsilon_{t} \\
\delta_{0}^{s} s_{t}
\end{array}\right)=\underbrace{\left(\begin{array}{cc}
1 & 0 \\
\delta_{0}^{s} & \delta_{0}^{s}
\end{array}\right)}_{F}\left(\begin{array}{c}
\epsilon_{t} \\
e_{t}
\end{array}\right)
$$

To be able to identify the shocks $\epsilon_{t}$ and $e_{t}$ using $y_{t}$ and $E_{t}^{s}\left(y_{t}\right)$, we need $F$ to be invertible - which is the case - so that we could write $\left(\begin{array}{c}\epsilon_{t} \\ e_{t}\end{array}\right)=F^{-1}\left(\begin{array}{c}y_{t} \\ \bar{E}_{t}^{s}\left(y_{t}\right)\end{array}\right)$. It is easy here to recover fundamental and noise shocks, because noise shocks affect the survey expectations of $y_{t}$ but not $y_{t}$. This is because households know $\epsilon_{t}$ perfectly while nowcasters do not, which is a limit case of private information. It is a natural assumption given that we are considering current shocks hitting households. Importantly, the econometrician uses the actual realization of output, which is not contemporaneously available to nowcasters, as it is released ex post.

To understand how the absence of private information would lead to non-invertibility, suppose that now we were trying to use prices $p_{t}$ and their average expectation $E_{t}^{s}\left(p_{t}\right)$ to uncover $\epsilon_{t}$ and $e_{t}$ and that firms had no private information $\left(\left(\sigma_{1}^{f}\right)^{-2}=\delta_{1}^{f}=0\right)$ :

$$
\left(\begin{array}{c}
p_{t} \\
\bar{E}_{t}^{s}\left(p_{t}\right)
\end{array}\right)=\left(\begin{array}{c}
\kappa \delta_{0}^{f} s_{t} \\
\kappa \delta_{0}^{f} S_{t}
\end{array}\right)=\underbrace{\kappa \delta_{0}^{f}\left(\begin{array}{ll}
1 & 1 \\
1 & 1
\end{array}\right)}_{G}\left(\begin{array}{c}
\epsilon_{t} \\
e_{t}
\end{array}\right)
$$

Here, $G$ is not invertible. Despite the fact that we have two variables, we cannot recover the two shocks. Intuitively, this is because the only source of information is $s_{t}$, for economic agents (firms who set prices) and for nowcasters. The fundamental shock $\epsilon_{t}$ affects the economy only because it moves $s_{t}$, just like the noise shock $e_{t}$, and it does not have any effect beyond $s_{t}$. Prices and their expectations are thus not linearly independent. This is the issue highlighted by Blanchard et al. (2013). Note that it would be enough to assume that firms had some private information $\left(\left(\sigma_{1}^{f}\right)^{-2}>0\right.$ and hence $\left.\delta_{1}^{f}>0\right)$ to make $G$ invertible. Any amount of private information would in theory be enough to make the system invertible. ${ }^{10}$ However, in practice, because of small sample issues, agents should receive sufficiently precise private signals for their actions to depend on them in a substantial way.

\section{Assessing noise and fundamental shocks}

To gauge the contribution of demand and supply shocks to business cycles, we estimate a SVAR model in which structural shocks are identified through zero and sign restrictions, using the insights of Section 2. In particular, nowcast errors provide information regarding the source of agents' misperceptions of economic activity. We first describe the estimation strategy and the results, before turning to robustness checks.

\subsection{Estimation strategy}

\subsubsection{SVAR model}

The canonical $\operatorname{VAR}(p)$ model can be written as

$$
Y_{t}=\Phi(L) Y_{t}+v_{t}
$$

where $Y_{t}=\left(Y_{1, t}, \ldots, Y_{n, t}\right)^{\prime}$ is an $(n \times 1)$ vector of endogenous variables, $L$ is the lag operator, $\Phi$ is the $(n \times 1)$ matrix of estimated parameters and $v_{t}$ is an $(n \times 1)$ vector of reduced-form residuals such that $v_{t} \sim \operatorname{iid}(0, \Sigma)$, with $\Sigma$, a symmetric positive definite matrix. Canonical innovations, $v_{t}$, are related to structural innovations, $\xi_{t}$, by the linear combination $v_{t}=\Gamma \xi_{t}$, where structural shocks are, by assumption, orthogonalized, such that $\xi_{t} \sim \operatorname{iid}\left(0, \mathrm{I}_{n \times n}\right)$ and $\Gamma$ is a $(n \times n)$ nonsingular matrix. The matrix $\Sigma$ can be rewritten as $\Sigma=\tilde{\Gamma} Q Q^{\prime} \tilde{\Gamma}^{\prime}$, where $\tilde{\Gamma}$ is a Choleski decomposition of $\Sigma$ and $Q$ is an orthonormal matrix (i.e., $\left.Q Q^{\prime}=I_{n \times n}\right)$. There is an infinite number of eligible $Q s$, and structural shocks are therefore identified by imposing identifying zero and sign restrictions on the IRFs of selected variables to shocks.

To impose our set of restrictions, we follow Arias et al. (2018). We estimate $\Phi$ through a parametrized OLS. Following the Monte Carlo strategy suggested by Hamilton (1995), we randomly generate a set of coefficients $\hat{\Phi}(L)$ drawn from the asymptotic distribution of the estimated reduced-form parameters and a matrix $\hat{\Sigma}$ drawn from the asymptotic distribution of the variance-covariance matrix of the reduced-form residuals associated with the canonical VAR (Eq. (7)). We also draw a rotation matrix $Q$ from the set of rotation matrices satisfying the zero restrictions and then build the corresponding IRFs.

\footnotetext{
10 See the proof in the online appendix. We also show there that endowing nowcasters with private signals does not affect the invertibility of $G$. This is because nowcasters still do not have common knowledge with firms. As a result, $p_{t} \neq \bar{E}_{t}^{s}\left(p_{t}\right)$, which ensures invertibility.
} 
We select the set of IRFs that satisfy the sign restrictions among the K draws. This methodology takes into account both the uncertainty inherent to sign restrictions and the uncertainty of the estimated parameters in Eq. (7). ${ }^{11}$ The online appendix describes the full algorithm.

The baseline VAR model (Eq. (7)) includes the set of observables

$$
Y_{t}=\left[\Delta y_{t}, \pi_{t}, \mathrm{E}_{t}\left\{\Delta y_{t}\right\}-\Delta \tilde{y}_{t}, \mathrm{E}_{t}\left\{\pi_{t}\right\}-\tilde{\pi}_{t}\right]
$$

where $\Delta y_{t}$ is the annualized growth rate of real GDP and $\pi_{t}$ is the annualized GDP deflator inflation rate. Let $\mathrm{E}_{t}\left\{\Delta y_{t}\right\}-$ $\Delta \tilde{y}_{t}$ and $\mathrm{E}_{t}\left\{\pi_{t}\right\}-\tilde{\pi}_{t}$ denote the nowcast errors of real GDP growth and inflation, respectively. These are measured as the difference between the nowcast prediction of the variable (produced by the SPF of the Philadelphia Federal Reserve Bank) and their corresponding first-release observation. An alternative strategy would be to use the final-release series in the construction of the nowcast error. Fig. A3 in the online appendix shows that real GDP growth and inflation are subject to large data revisions. However, the final-release (or most recent release) series also incorporates changes in the national account methodology that cannot be anticipated by forecasters and might bias our results (Croushore, 1993). The online appendix describes the data. In the baseline estimation, we use all available data over the sample 1969q2-2017q1.

\subsubsection{Set of identifying restrictions}

We seek to identify supply, supply noise, demand and demand noise shocks. The set of restrictions that we use is summarized in Table 1. We follow Blanchard and Quah (1989) and impose all shocks except the fundamental supply shock to have no long-run effect on real GDP. In Blanchard and Quah (1989), demand shocks are the only transitory shocks. In our approach, demand, supply noise and demand noise shocks are all transitory. We disentangle them by imposing sign restrictions on the impact IRFs.

We first impose restrictions on the errors. As explained in Section 2, assuming that positive fundamental demand shocks drive a positive response of output growth and inflation, they should lead nowcasters to underestimate both variables, while positive demand noise shocks should lead nowcasters to overestimate them. Similarly, assuming that positive fundamental supply shocks drive a positive response of output growth and a negative response of inflation, positive supply noise shocks should lead nowcasters to overestimate output growth and underestimate inflation. Imposing the restriction that supply noise shocks affect the expectation errors in the opposite direction while demand and demand noise shocks affect them in the same direction helps us to distinguish supply noise shocks from demand and demand noise shocks. It also ensures that demand and demand noise shocks are not confused with temporary supply shocks (such as oil shocks or markup shocks). Indeed, since these shocks drive opposing responses of output and inflation, their errors should also move in opposite directions.

Restricting the errors is not sufficient to distinguish fundamental positive demand shocks from negative demand noise. To do so, it is enough to assume that positive fundamental demand and demand noise shocks both drive a positive response of inflation. This hinges on the assumption that firms, upon receiving a positive signal about demand, increase their prices, as described in Section 2. Similarly, negative supply noise shocks could be confused with positive temporary fundamental supply shocks that would drive the same response of errors. It is then enough to assume that supply noise drives a positive response of output growth. This hinges on the assumption that households, upon receiving a positive signal about supply, increase their consumption (see Lorenzoni, 2009).

All other signs are left unrestricted. This identification strategy allows us to let the data speak regarding the effects of fundamental demand and demand noise shocks on output and of supply noise shocks on inflation. Long-run restrictions result in a lag-truncation bias, which leads us to select eight lags (Chari et al., 2008).12

\subsection{Benchmark estimation}

\subsubsection{Impulse response analysis}

Fig. 2 shows the median responses of real GDP (in level), the inflation rate and their relative nowcast errors to the fundamental and noise shocks, along with the $16 \%$ and $84 \%$ quantiles, as suggested by Uhlig (2005). These bands can be interpreted as confidence intervals since we resort to a Monte Carlo procedure to take into account the uncertainty of estimated parameters in the SVAR model. One main result emerges from Fig. 2: Although the response of GDP to a demand noise shock has been left unrestricted, we find that this shock is recessionary. Although this result might seem puzzling, we will show in Section 4 that it can be rationalized by a monetary policy channel. The other responses to demand noise shocks simply reflect the restrictions of Table 1 .

Fig. 2 provides additional results. First, supply noise and fundamental demand shocks generate responses of a similar shape in output and inflation, as suggested by Lorenzoni (2009), even though the response of inflation to supply noise shocks and the response of output to demand shocks are left unrestricted. Second, we restrict only the impact responses, so the persistence of the responses is a genuine result. The effects of supply noise and demand noise shocks on output

\footnotetext{
${ }^{11}$ The only difference between our procedure and the one suggested by Arias et al. (2018) is that they draw $\hat{\Sigma}$ and $\hat{\Phi}(L)$ from the posterior distribution of a Bayesian VAR, whereas we use the asymptotic distribution of the parameters. In fact, our methodology coincides with theirs when the prior distributions are flat.

${ }^{12}$ In the online appendix, we show that our results are robust to the use of 12 lags.
} 

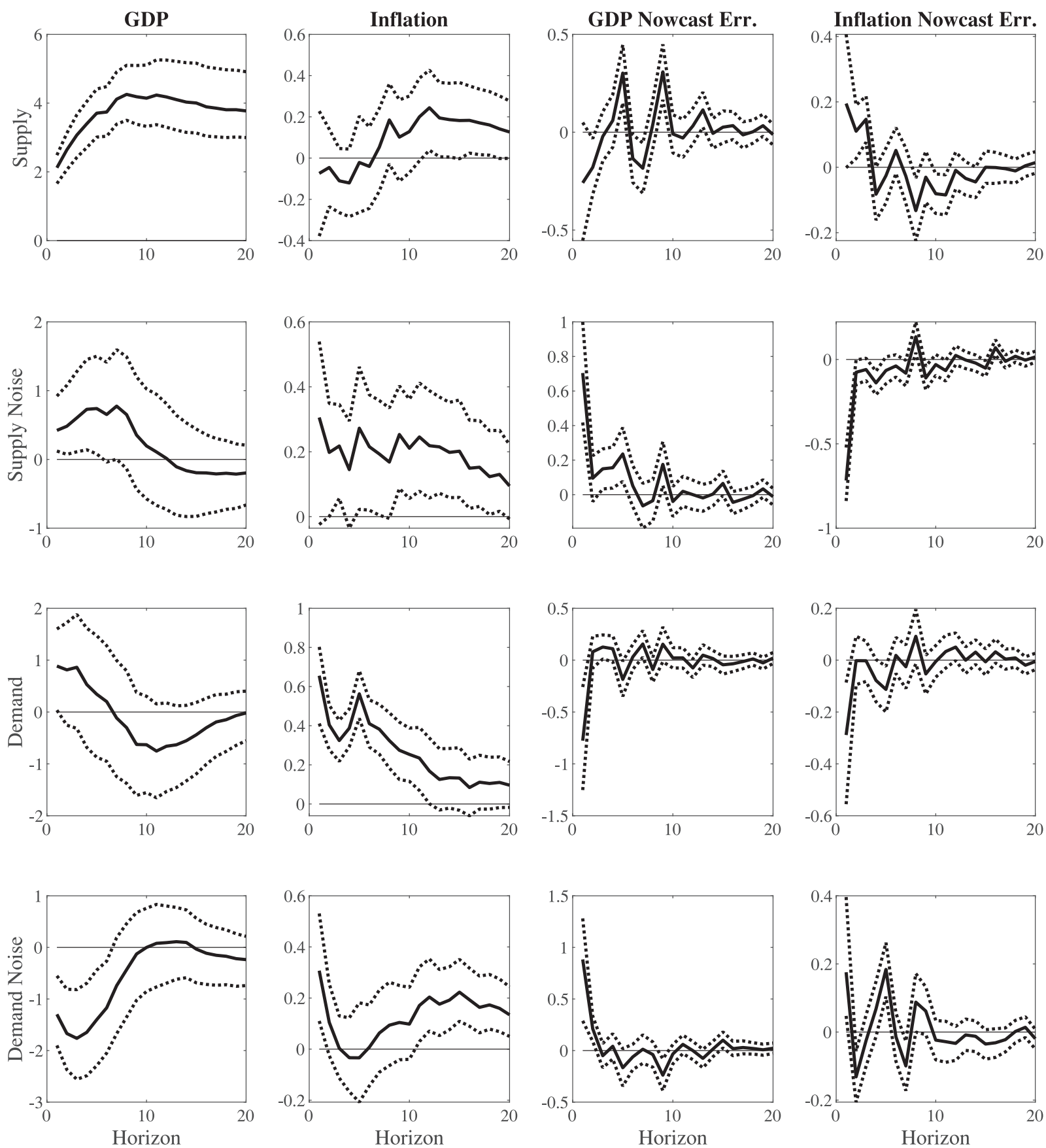

Fig. 2. IRFs - Benchmark Estimation. Note: The solid lines depict the median impulse response function. The lower and upper dotted lines indicate the 16th and 84th percentile region, respectively. Identification restrictions follow Table 1.

Table 1

Baseline identification strategy.

\begin{tabular}{lllll}
\hline & $y_{t}$ & $\pi_{t}$ & $E_{t}\left(\Delta y_{t}\right)-\tilde{y}_{t}$ & $E_{t}\left(\pi_{t}\right)-\tilde{\pi}_{t}$ \\
\hline Fundamental supply & $>0$ permanently & $\times$ & $\times$ & $\times$ \\
Supply noise & $>0$ & $\times$ & $>0$ & $<0$ \\
Fundamental demand & $\times$ & $>0$ & $<0$ & $<0$ \\
Demand noise & $\times$ & $>0$ & $>0$ & $>0$ \\
\hline
\end{tabular}

Note: The response of GDP is constructed by taking the sum of the cumulated response of GDP growth. Signs are imposed on the impact responses. A cross corresponds to an unrestricted sign. 
Table 2

Baseline estimation: unconditional variance decomposition.

\begin{tabular}{lllll}
\hline & Supply & Supply noise & Demand & Demand noise \\
\hline GDP growth & $0.47[0.33,0.61]$ & $0.08[0.04,0.15]$ & $0.15[0.07,0.30]$ & $0.23[0.10,0.39]$ \\
Inflation & $0.17[0.07,0.37]$ & $0.19[0.04,0.42]$ & $0.36[0.16,0.60]$ & $0.14[0.06,0.29]$ \\
GDP Nowcast err. & $0.16[0.10,0.23]$ & $0.22[0.13,0.34]$ & $0.25[0.12,0.48]$ & $0.30[0.13,0.51]$ \\
Inflation Nowcast err & $0.16[0.09,0.25]$ & $0.48[0.27,0.62]$ & $0.15[0.07,0.33]$ & $0.14[0.09,0.23]$ \\
\hline
\end{tabular}

Note: For each successful draw, the unconditional variance decomposition is computed. The upper number reports the median value and numbers under brackets are the 16th and 84th percentile values of the variance decomposition distribution.

and inflation are persistent, suggesting that informational frictions have short but also medium-run effects and that information frictions are paramount among agents. Conversely, the responses of nowcast errors to all shocks are short lived, suggesting that professional forecasters update their information quickly. This contrasts with the finding of Coibion and Gorodnichenko (2012), who show that forecast errors are persistent. This apparent conflicting result is in line with Enders et al. (2018)'s argument that nowcasts move more rapidly than forecasts.

These empirical findings confirm Lorenzoni (2009)'s prediction that supply noise shocks look like demand shocks, but also expand on it. Indeed, we highlight that demand noise shocks look like (negative) supply shocks. An important question is: Could this result be driven by the fact that our methodology confuses demand noise shocks with temporary supply shocks? This is particularly important to address, because we do not separately identify temporary supply shocks. In fact, as long as temporary supply shocks drive a negative correlation between output growth and inflation, they should also drive a negative correlation between the corresponding errors. Because we impose the restriction that demand noise shocks drive a positive correlation between the errors, they cannot be confused with temporary supply shocks. ${ }^{13}$

\subsubsection{Variance decomposition}

The variance decomposition of output growth and inflation is a useful tool to assess whether noise matters for the business cycle. We compute the unconditional variance decomposition of a variable for each successful draw of our SVAR. Table 2 provides the median of the unconditional variance decomposition for GDP growth, inflation and their nowcast error counterpart, as well as the $16 \%$ and $84 \%$ quantile values.

Starting with noise shocks, we find that they explain in total $31 \%$ of output growth fluctuations. Most of this contribution is attributable to demand noise shocks since they contribute to about 23\% of GDP growth volatility - while supply noise shocks explain only 8\%. Enders et al. (2018) show that "optimism" (or noise) shocks contribute to 15\% of short-term GDP volatility. ${ }^{14}$ Blanchard et al. (2013) also investigate in a fully-fledged dynamic stochastic general equilibrium model the contribution of noise shocks: They find that these account for $20 \%$ of output volatility. In our setup, which allows for demand noise shocks, we capture a lower contribution of supply noise, but a larger contribution of noise taken in a broad sense.

Regarding fundamental shocks, Table 2 shows that demand shocks contribute to $15 \%$ of output growth volatility, while supply shocks explain $47 \%$ of it, which is in the same range as Francis and Ramey (2006). Fig. A5 in the online appendix provides the variance decomposition of GDP (in level) at different horizons. Fundamental supply shocks explain - by construction - most of the variance of GDP over the long run, while demand noise shocks explain almost one-fourth of the short-run fluctuations. Table 2 also shows that the bulk of the variance of inflation is explained by demand shocks (36\%) and noise shocks (33\%). This finding echoes Dedola and Neri (2007), who argue that TFP shocks explain only a small share of inflation volatility.

Fig. A6 in the online appendix shows the historical decomposition of fundamental and noise shocks. The contribution of demand and demand noise shocks is stronger at the beginning of the sample (before the Great Moderation), but demand noise shocks contribute a non-negligible amount to the Great Recession.

\subsection{Robustness}

Benchmark results obtained in the previous section suggest that noise shocks - and in particular demand noise shocks - explain a substantial part of GDP and inflation fluctuations. We now run a series of robustness checks. Table 3 gives the variance decomposition of GDP growth in the different specifications. The variance decomposition of other variables, as well as their associated IRFs, are in the online appendix (Tables A7 and A8 and Figs. A8-A11).

\subsubsection{Alternative identifying restrictions}

In the benchmark estimation, we use the long-run and sign restrictions provided in Table 1. In Panels $(b)$ to $(d)$ of Table 3 , we modify these restrictions. Panels $(b)$ and $(c)$ relax some restrictions, to rely only on errors to identify the noise shocks.

\footnotetext{
13 Because temporary supply shocks do not fit with any of the temporary shocks that we identify (supply noise, demand and demand noise), they would be subsumed under the supply shock - the only shock on which no restrictions are imposed - neither zero nor sign restriction.

14 Similarly, Hürtgen (2014) shows that consumer misperception shocks explain about 10\% of the business cycle.
} 
Table 3

Robustness: output growth unconditional variance decomposition.

\begin{tabular}{lllll}
\hline & Supply & Supply noise & Demand & Demand noise \\
\hline (a) Benchmark & $0.47[0.33,0.61]$ & $0.08[0.04,0.15]$ & $0.15[0.07,0.30]$ & $0.23[0.10,0.39]$ \\
(b) Relax noise supply & $0.44[0.31,0.58]$ & $0.10[0.06,0.17]$ & $0.16[0.09,0.28]$ & $0.24[0.12,0.40]$ \\
(c) Relax noise demand & $0.45[0.32,0.58]$ & $0.09[0.05,0.16]$ & $0.17[0.09,0.32]$ & $0.23[0.10,0.39]$ \\
(d) Sign restrictions only & $0.46[0.33,0.59]$ & $0.10[0.06,0.17]$ & $0.17[0.09,0.31]$ & $0.21[0.11,0.35]$ \\
(e) Great Moderation & $0.28[0.18,0.41]$ & $0.16[0.10,0.29]$ & $0.30[0.17,0.44]$ & $0.19[0.12,0.31]$ \\
(f) Third Release & $0.42[0.26,0.57]$ & $0.13[0.08,0.19]$ & $0.18[0.12,0.30]$ & $0.20[0.11,0.38]$ \\
(g) Mean Nowcast & $0.47[0.34,0.57]$ & $0.14[0.09,0.21]$ & $0.17[0.12,0.26]$ & $0.18[0.12,0.29]$ \\
(h) Three-variables SVAR & $0.70[0.50,0.82]$ & $0.09[0.5,0.18]$ & $0.19[0.10,0.34]$ & -
\end{tabular}

Note: Panel (a) corresponds to the benchmark estimation. In Panel $(b)$, the response of output to supply noise shock is left unrestricted. In Panel $(c)$, the response of inflation to demand noise shock is left unrestricted. In Panel $(d)$, long-run restrictions are relaxed, output growth and nowcast errors of inflation to respond positively to the fundamental supply shock and nowcast errors on output respond negatively. In Panel $(e)$, the baseline SVAR model is estimated over the sample 1983q2-2007q2. In Panel $(f)$, the nowcast errors on output growth and inflation are computed as the difference between the nowcast predictions of the variables and their third release observations. In Panel $(g)$, the nowcast variables of output growth and inflation correpond to the mean nowcast predictions. In Panel $(h)$, nowcast errors on inflation are dropped from the baseline SVAR model. The IRFs as well as the unconditional variance decomposition of inflation and nowcast errors for these robustness exercises are provided in the online appendix, Figure A8-A11 and Tables A10-A11, respectively.

More precisely, in Panel $(b)$, we relax the sign of the response of output to supply noise shocks. Similarly, in Panel (c), we relax the sign of the response of inflation to demand noise shocks. In Panel $(d)$, we relax the long-run restrictions. Instead, we impose output growth and nowcast errors of inflation to respond positively to the supply shock and nowcast errors of output to respond negatively.

Panels $(b)$ to $(d)$ in Table 3 show that the variance decomposition of output growth is robust to the identification strategy. This result also holds for other variables; see the online appendix, Tables A7 and A8. Importantly, we also show in Fig. A11 of the online appendix that the recession generated by demand noise shock is still significant in Panel $(c)$. In contrast, there is no clear-cut conclusion regarding the sign of the output's response to supply noise shocks in the unrestricted case of Panel $(b)$, which suggests that restrictions on nowcast errors are not sufficient to disentangle supply noise from transitory supply shocks, as also argued in Section 4.

\subsubsection{Alternative specifications}

In Panel $(e)$, the sample is restricted to the period 1983q2-2007q2 so as to capture the Great Moderation period. Interestingly, we find that supply shocks contribute significantly less to output growth volatility than in the baseline model ( $28 \%$ versus $47 \%$, respectively), while demand shocks become the largest contributors to output growth fluctuations (30\%). ${ }^{15}$ Regarding noise shocks, we find that their overall contribution to GDP volatility is similar to the benchmark, that is, 35\% altogether. However, the contribution of demand noise shocks is reduced (19\% versus $23 \%$ in the benchmark, although the difference is not significant), while the contribution of supply noise shocks is higher (16\% versus $8 \%$ ). This result indicates that the influence of noise shocks has changed over time. It is widely accepted that the Great Moderation period was characterized by a shift in the focus of the monetary policy in favor of price stability, which leads us to investigate more deeply the role of central bank decisions in the transmission channels of noise shocks. Section 4.3 focuses on this analysis.

In Panel (f), we compute the nowcast error of output growth and inflation as the difference between the nowcast prediction of these variables and their third-release counterparts. The third-release observations capture newly available (and revised) data sources that are missing in the first release, but it is more likely that they abstract from changes in national account methodology than the final-release data. ${ }^{16}$ Indeed, Croushore and Stark (2003) argue that data revisions might affect empirical results since they include new sets of information and since they reflect modifications in the national accounting methodology. The contribution of demand noise shocks to GDP fluctuations is slightly lessened compared with the benchmark estimation when third-release observations are used in the construction of the nowcast errors (20\% versus $23 \%$ ), while that of supply noise shocks is amplified (14\% versus 8\%). Section 6 in the online appendix provides additional robustness checks with the use of revised data.

Finally, in Panel $(g)$, we use the mean nowcast value of GDP growth and inflation rather than the median value to compute the nowcast error. The contribution of demand noise shocks is slightly reduced compared with the benchmark model $(18 \%)$, while that of supply noise shock is slightly larger (14\%). Therefore, the results in Panels $(f)$ and $(g)$ suggest that the construction of the nowcast errors series has some implications in the magnitude of the contribution of noise shocks (in particular, supply noise shocks), but in all cases, we shed light on the large contribution of noise shocks in the business cycle.

\footnotetext{
15 It may be that before the Great Moderation, oil shocks were an important source of supply shocks.

16 Notice that the Bureau of Economic Analysis performs comprehensive updates of National Income and Product Accounts every five years, the most recent one being in 2018. These updates include substantial modifications in the national accounting methodology.
} 


\subsubsection{Omitting demand noise shocks}

Panel $(h)$ illustrates how the variance decomposition is affected when we disregard demand noise shocks, as is usually done. We remove the nowcast error of inflation from the SVAR model and focus our estimation on fundamental shocks and supply noise shocks. The identification strategy is similar to our benchmark case: Supply shocks are the only shocks to have a permanent effect on GDP; demand shocks are inflationary, but they lead forecasters to underestimate output (negative GDP nowcast error on impact); and supply noise shocks increase output and its corresponding nowcast error about impact. The contribution of the supply noise and fundamental demand shocks to GDP fluctuations, reported in Panel $(h)$ of Table 3, are similar to the baseline model ( $9 \%$ and 19\%, respectively). The overall contribution of noise shocks is thus underestimated. In contrast, the contribution of supply shocks - which generate the same effects on output and inflation as negative demand noise shocks - is overestimated (70\% versus $47 \%$ ). This result suggests that supply shocks capture the fluctuations inherent to demand noise shocks when the latter are omitted.

\section{A structural interpretation of the results}

Here, we develop a noisy-information extension of a New Keynesian model à la Galì (2008) with both supply (technology) and demand (preference) shocks. The information structure is similar to the reduced-form model presented in Section 2. The model serves two purposes. First, it rationalizes our set of restrictions in a structural model. Second, it helps us to understand the effect of noise shocks, particularly demand noise shocks, in the economy. We first present the model and the solution in a limit case. Then, the model is parametrized, and we use it to analyze the transmission channels of demand noise shocks and to analyze their large contribution to output fluctuations.

\subsection{A dispersed-information New Keynesian model}

There is a continuum [0,1] of households who work and consume a final good, a continuum [0,1] of islands, each inhabited by a continuum [0,1] of oligopolistic firms producing differentiated intermediate goods and by a competitive firm using the differentiated goods to produce a final good. Households own equal shares in the firms. They buy final goods produced in one of the production islands and supply labor in a centralized labor market. That is, each period, nature randomly selects an island $l(i, t) \in[0,1]$ visited by household $i$ to shop. Similarly, firms of island $i$ are visited by a household $k(i, t) \in[0,1]$ to shop.

Household $i \in[0,1]$ decides both its consumption $C_{i t}$ and its labor supply $N_{t}^{i}$ by maximizing the expected value of the household's utility: $\sum_{s=0}^{\infty} B_{t+s}\left\{\log \left(C_{i t+s}\right)-\frac{1}{1+\zeta}\left(N_{t+s}^{i}\right)^{1+\zeta}\right\}$, where $\zeta$ is the inverse of the Frisch elasticity of labor supply and $B_{t}$ is the coefficient of time preference for date $t$ defined by $B_{t}=\beta B_{t-1} e^{-u_{t-1}^{b}} ; \beta$ is the average time discount factor and $u_{t}^{b}$ is an intertemporal time preference shifter following the process $u_{t}^{b}=\rho_{b} u_{t-1}^{b}+\epsilon_{t}^{b}$, with $\epsilon_{t}^{b} \sim N\left(0, \sigma_{b}^{2}\right)$. Household $i$ then faces the following budget constraint: $\left(1+i_{t}\right) D_{i t+1}+\int_{0}^{1} P_{j t} C_{i j t} d j+\int Q\left(\omega_{i t}\right) Z_{i t+1}\left(\omega_{i t}\right) d \omega_{i t}=D_{i t}+W_{t} N_{t}^{i}+\int_{0}^{1}\left(\int_{0}^{1} P_{j t} Y_{j t} d j\right) d i+$ $Z_{i t}\left(\omega_{i t-1}\right)$, where $D_{i t+1}$ denotes the nominal deposits, $W_{t}$ is the nominal wage, $\omega_{i t}$ denotes the state, which depends on the set of aggregate and idiosyncratic shocks that occur in the second stage, $Q\left(\omega_{i t}\right)$ is the unit price of a contingent claim that delivers 1 in state $\omega_{i t}$, and $Z_{i t+1}\left(\omega_{i t}\right)$ are the quantities of contingent claims bought by the household. We assume that households are fully insured, which eliminates heterogeneity across households.

Each firm $j \in[0,1]$ on island $i \in[0,1]$ produces a type- $j$ good using a quantity of labor $N_{i j i}$, with the production function $Y_{i j t}=A_{t} N_{i j t}$, where $A_{t}$ is TFP. It sells the good at price $P_{i j t}$ to the island's final good firm. The final good firm uses the differentiated goods supplied on the island to produce the final good, following $Y_{i t}=\left(\int_{0}^{1} Y_{i j t}^{(\gamma-1) / \gamma} d j\right)^{\gamma /(\gamma-1)}$, with $\gamma>0$. Let $A_{t}=\bar{A} e^{u_{t}^{a}}$, where $u_{t}^{a}$ follows a random walk $u_{t}^{a}=u_{t-1}^{a}+\epsilon_{t}^{a}$, with $\epsilon_{t}^{a} \sim \mathcal{N}\left(0, \sigma_{a}\right)$. Notice that technology shocks are permanent, while preference shocks are transitory. Nominal rigidities in price setting follow Calvo (1983): Each period, a fraction $1-\theta$ of island $i$ firms are able to re-optimize their prices.

The central bank sets the interest rate on nominal one-period deposits according to the rule $i_{t}=\bar{\imath}+\varphi E_{t}^{g}\left(\pi_{t}\right)$, where $\pi_{t}=p_{t}-p_{t-1}$, with $p_{t}=\log \left(P_{t}\right)$ the average price of the final good across islands, and $E_{t}^{g}($.$) is the expectation of the central$ bank.

We assume that pricing of the intermediate goods, consumption of the final good and interest-rate-setting decisions are taken at the beginning of the period, before the goods, labor and bond markets open. Production (and hence labor demand) decisions take place at the end of the period to serve the demand for goods. Labor supply decisions also take place at the end of the period at the wage rate that clears the market and hence reflects the households' marginal rate of substitution between labor and consumption.

There is a continuum [0,1] of nowcasters who publish output and inflation nowcasts. These nowcasts do not affect the economy, but they are observed by the econometrician.

\subsubsection{Information}

Here, we describe the information set conditional on which agents form their economically relevant expectations and the information conditional on which nowcasters build their nowcasts. The average of these nowcasts is what we call survey 
expectations. It generalizes the information structure of the reduced-form model of Section 2 . We assume that agents do not observe the shocks currently hitting the economy, and learn about past aggregate shocks and past prices after $T$ periods. However, in a given period, firms learn technology $u_{t}^{a}$ and households learn their preferences $u_{t}^{b}$. Moreover, agents receive public and private signals on current shocks.

We assume that all agents receive a public signal on $u_{t}^{a}, s_{t}^{a}=u_{t}^{a}+e_{t}^{a}$, with $e_{t}^{a} \sim \mathcal{N}\left(0, \sigma_{0 a}\right)$, and a public signal on $u_{t}^{b}$, $s_{t}^{b}=u_{t}^{b}+e_{t}^{b}$, with $e_{t}^{b} \sim \mathcal{N}\left(0, \sigma_{0 b}\right) ; e_{t}^{a}$ and $e_{t}^{b}$ are, respectively, the productivity (supply) and preference (demand) noise shocks, while $\epsilon_{t}^{a}$ and $\epsilon_{t}^{b}$ are the corresponding fundamental shocks.

Moreover, firms on island $i$ receive a private signal on $u_{t}^{b}, x_{i t}^{b f}=u_{t}^{b}+\lambda_{i t}^{b f}$, and each household $i$ receives a private signal on $u_{t}^{a}, x_{i t}^{a c}=u_{t}^{a}+\lambda_{i t}^{a c}$. Nowcaster $i$ receives private signals on both technology and preferences: $x_{i t}^{a s}=u_{t}^{a}+\lambda_{i t}^{a s}$ and $x_{i t}^{b s}=u_{t}^{b}+$ $\lambda_{i t}^{b s}$. The idiosyncratic noise shocks $\lambda_{i t}^{n m}$ follow $\mathcal{N}\left(0,\left(\sigma_{n 1}^{m}\right)^{2}\right)$ and satisfy $\int_{0}^{1} \lambda_{i t}^{n m} d i=0$, for $\{n, m\}=\{a, c\},\{b, f\},\{a, s\},\{b, s\}$. Agents' expectations are defined as follows: $E_{i t}^{m}(),. m=c, f, s$, where $c$ is for households, $f$ for firms and $s$ for nowcasters.

Finally, the central bank observes the public signals but does not have access to any private source of information. This assumption reflects the idea that the central bank communication is transparent: Upon setting its interest rate, the central bank communicates whatever private information it has, so the central bank information becomes public. It is subsumed in the public signals $s_{t}^{a}$ and $s_{t}^{b}$.

We assume that the agents do not use endogenous signals to form expectations. Although unrealistic, this assumption allows a more transparent analysis and is common in the literature. ${ }^{17}$ The assumption that agents learn past variables after $T$ reduces the dimensionality issue that is typical of higher-order beliefs. Indeed, in our setup, higher-order beliefs are generated by the presence of asymmetric information among and between firms and households. Finally, modeling production units as islands with common information suppresses the higher-order beliefs of firms regarding their competitors and allows us to focus on the firms' imperfect information about demand.

\subsubsection{A limit case}

To understand the intuition of the mechanism, it is useful to focus on the case where agents learn last-period shocks $(T=1)$, and demand shocks are i.i.d. $\left(\rho_{b}=0\right)$. In this case, the New Keynesian model under imperfect information boils down to the following aggregate Euler equation and Phillips curve (see details in Section 1 of the online appendix):

$$
\begin{aligned}
& c_{t}=u_{t-1}^{a}+\bar{E}_{t}^{c}\left(\epsilon_{t}^{a}\right)-\varphi E_{t}^{g}\left(\pi_{t}\right)+\epsilon_{t}^{b} \\
& \pi_{t}=\kappa\left(\bar{E}_{t}^{f}\left(c_{t}\right)-u_{t}^{a}\right)+\frac{1-\theta}{\theta}\left[\bar{E}_{t}^{f}\left(\pi_{t}\right)-\pi_{t}\right]
\end{aligned}
$$

where $\kappa=(1+\zeta)(1-\theta)(1-\beta \theta) / \theta$ is the slope of the New Keynesian Phillips curve (NKPC). $\bar{E}_{t}^{m}()=.\int_{0}^{1} E_{i t}^{m}() d i,. m=c, f$, denote the households' and firms' average expectations. The aggregate Euler equation (Eq. (9)) depends on households' expectations about technologytechnology (through their expectations about future consumption)", on the central bank's expectations about inflation (through the nominal interest rate) and on the preference shock. The NKPC (Eq. (10)) links inflation to the average firm's expected marginal cost. The marginal cost is proportional to the deviation of aggregate demand $c_{t}$ from capacity output, which corresponds to the state of technology $u_{t}^{a}$. An additional term in the NKPC captures deviations of actual inflation from the firms' average expectations. This term might be different from zero since firms do not have common knowledge. Here, we use the assumption that agents learn past technology and that shocks are i.i.d., to suppress expected future inflation and higher-order beliefs about future prices from the Euler equation and the Phillips curve, and to write future expected consumption as the past level of technology plus the expected current technology innovation, reflecting the permanent-income hypothesis.

This model can rationalize our restrictions in Table 1 and explain the negative effect of demand noise shocks on output. In Section 2.4 of the online appendix, we derive the effect of shocks on output, inflation and the errors in closed form. Here, we give only the intuition. A demand shock $\left(\epsilon_{t}^{b}\right)$ has a positive effect on output, due to the shift in aggregate demand, and on inflation, due to the firms' expectations of a rise in the marginal cost. Similarly, a supply shock $\left(\epsilon_{t}^{a}\right)$ has a positive effect on output, due to the households' expectations of a rise in their permanent income, and a negative effect on inflation, due to the decline in marginal cost. The effect of fundamental and noise shocks on the survey expectation errors $\bar{E}_{t}^{s}\left(y_{t}\right)-y_{t}$ and $\bar{E}_{t}^{s}\left(\pi_{t}\right)-\pi_{t}$ then arises naturally, as explained in Section 2 .

Now consider the effects of noise shocks on the economy. A supply noise shock $\left(e_{t}^{a}\right)$ has a positive effect on output because it affects positively households' expectations on their permanent income, as apparent in Eq. (9). It has a positive effect on inflation because the increase in aggregate demand pushes the marginal cost up, as apparent in Eq. (10). This is consistent with our empirical results, where we indeed find that supply noise shocks are inflationary. These results are also in line with Lorenzoni (2009).

\footnotetext{
17 See, for instance, Woodford (2003), Angeletos and La'O (2009), Nimark (2014), Melosi (2014) or Angeletos et al. (2018).
} 
We find that a demand noise shock $\left(e_{t}^{b}\right)$ is recessionary in this model, which is consistent with our empirical results. This comes from a monetary policy channel: As the central bank receives a positive signal about demand, it expects a rise in inflation and increases the interest rate accordingly. This rise in interest rate then depresses aggregate demand (see Eq. (9)). Finally, contrary to our reduced-form model, our New Keynesian model does not predict a clear-cut effect of demand noise on inflation. In particular, if firms have very precise private signals, they expect a policy-driven recession and decrease their prices. However, as we explained in Section 3.3, relaxing the restriction that demand noise should be inflationary in our empirical exercise does not change our results.

\subsubsection{Assessing sign restrictions}

In Section 5 of the online appendix, we assess the validity of our sign restrictions using an extended version of the model, where (1) we allow the Taylor rule to react to the central bank's assessment of the output gap, (2) we relax the assumption that the central bank has no private information by allowing the central bank to use private signals about the fundamental shocks and (3) we assume that firms use an intermediate input that is composed of other differentiated goods. In that case, firms are allowed to make quantity decisions conditional on their expectations of the state of demand, so that demand noise shocks can also have a positive effect on aggregate demand. We fix preference, policy and technology parameters following the literature and assume a broad range for the other parameters, particularly the parameters related to the information structure. We perform 1,000 simulations where the parameters are randomly drawn from their assumed range, and store the sign of the impact responses. Table A3 in the online appendix shows that restrictions on errors are particularly robust. Only the restriction that inflation responds positively to the demand noise is not systematically satisfied (although it is satisfied for $98 \%$ of the simulations).

In Section 4.3 of the online appendix, we further extend the model to include other types of demand shocks (government spending and monetary policy shocks) and examine how these shocks and their corresponding noise affect the responses. Using the same methodology, we show that government spending and monetary shocks generate the same type of responses as the preference shocks. With our methodology, we are thus able to capture a broad variety of demand shocks. Finally, we allow aggregate TFP to be driven by temporary shocks as well: We show that they drive a negative correlation between the errors about output and inflation, so it is important to restrict the response of output to supply noise to avoid confusing them with temporary supply shocks.

\subsection{Parametrization}

Let $\psi^{c}=\left(\beta, \kappa, \zeta, \gamma, \varphi, \rho_{b}, T\right)^{\prime}$ denote the vector of calibrated parameters. We choose $\beta=0.99$, implying an annual interest rate of about $4 \%$. The Calvo parameter is set to $\theta=0.65$, implying an average price duration of about three quarters and an NKPC slope $\kappa=0.192$. As is standard, the Frisch parameter $1 / \zeta$ is set to 1 , the elasticity of demand for individual goods, $\gamma$, is set to 7.5, and the elasticity of the interest rate to expected inflation in the Taylor rule, $\varphi$, is set to 2 . Finally, we set the persistence of preference shocks $\rho_{b}$ to 0.9. $T$ is set to 30 to mimic $T=+\infty$. Setting $T$ beyond 30 did not affect our results.

The remaining parameters are the standard deviation of shocks, summarized in the vector $\psi^{e}=$ $\left(\sigma_{a}, \sigma_{0 a}, \sigma_{1 a}^{c}, \sigma_{1 a}^{s}, \sigma_{b}, \sigma_{0 b}, \sigma_{1 b}^{f}, \sigma_{1 b}^{s}\right)^{\prime}$. These parameters are related to the magnitude of fundamental shocks and the precision of the public and private signals. The set of parameters $\psi^{e}$ is estimated through indirect inference (see Gouriéroux et al., 1993), where we use the SVAR model estimated in Section 3 as an auxiliary model. We generate 500 series of 150 observations using the theoretical model. Our benchmark SVAR model is then estimated on the basis of these artificial data. The model's parameters are chosen so that the conditional standard deviations up to the fifth quarter obtained using the SVAR on the artificial data is as close as possible to their counterparts obtained using the SVAR on the real data (more details are in Section 5 of the online appendix). We restrict the horizon to five quarters because our model is too stylized to generate the same persistence as in the data.

Table 4 reports the estimated parameters, along with the empirical and theoretical moments. For each empirical moment, we provide the median as well as the 16th and 84th percentile. Most of the model-based estimated moments are within the confidence interval. To assess the goodness of fit of the theoretical model, Fig. A7 in the online appendix provides the SVAR-based IRFs computed from both empirical and artificial data (as well as the theoretical IRFs based on the estimated structural model). Despite its lack of persistence, the theoretical model does a good job of replicating the empirical evidence.

\subsection{Inspecting the mechanisms}

We now use the estimated model to emphasize two features that determine the contribution of demand noise shocks to output fluctuations, namely, monetary policy and firms' information. 
Table 4

Indirect inference parametrization.

\begin{tabular}{|c|c|c|c|c|c|}
\hline \multicolumn{6}{|l|}{ Parameters } \\
\hline & \multicolumn{2}{|l|}{8.02} & \multicolumn{3}{|c|}{ Variance of fundamental supply } \\
\hline & \multicolumn{2}{|l|}{10.62} & \multicolumn{3}{|c|}{ Variance of supply noise } \\
\hline$\left(\sigma_{a 1}^{c}\right)^{2}$ & \multicolumn{2}{|l|}{9.37} & \multicolumn{3}{|c|}{ Variance of idiosyncratic consumers' supply noise shock } \\
\hline$\left(\sigma_{a 1}^{s}\right)^{2}$ & \multicolumn{2}{|l|}{993} & \multicolumn{3}{|c|}{ Variance of idiosyncratic nowcasters' supply noise shock } \\
\hline$\sigma_{b}^{2}$ & \multicolumn{2}{|l|}{0.86} & \multicolumn{3}{|c|}{ Variance of fundamental demand } \\
\hline & \multicolumn{2}{|l|}{1.45} & \multicolumn{3}{|l|}{ Variance of demand noise } \\
\hline$\left(\sigma_{b 1}^{f}\right)^{2}$ & \multicolumn{2}{|l|}{$\begin{array}{l}0.69 \\
999\end{array}$} & \multirow{2}{*}{\multicolumn{3}{|c|}{$\begin{array}{l}\text { Variance of idiosyncratic firms' demand noise shock } \\
\text { Variance of idiosyncratic nowcasters' demand noise shock }\end{array}$}} \\
\hline$\left(\sigma_{b 1}^{s}\right)^{2}$ & 999 & & & & \\
\hline Matched moments & Data & \multicolumn{2}{|l|}{ Baseline } & Data & Baseline \\
\hline$\sigma\left(\Delta y_{t} \mid \epsilon_{t}^{a}\right)$ & $2.2[1.82,6]$ & 1.83 & $\sigma\left(\Delta y_{t} \mid \epsilon_{t}^{b}\right)$ & $1.10[0.81,1.3]$ & 1.52 \\
\hline$\sigma\left(\Delta y_{t} \mid e_{t}^{a}\right)$ & $0.66[0.46,1]$ & 0.95 & $\sigma\left(\Delta y_{t} \mid e_{t}^{b}\right)$ & $1.50[0.84,2]$ & 1.23 \\
\hline$\sigma\left(\pi_{t} \mid \epsilon_{t}^{a}\right)$ & $0.39[0.2,0.74]$ & 0.53 & $\sigma\left(\pi_{t} \mid \epsilon_{t}^{b}\right)$ & $1.10[0.81,1.3]$ & 1.09 \\
\hline$\sigma\left(\pi_{t} \mid e_{t}^{a}\right)$ & $0.54[0.23,0.89]$ & 0.62 & $\sigma\left(\pi_{t} \mid e_{t}^{b}\right)$ & $0.41[0.28,0.65]$ & 0.46 \\
\hline$\sigma\left(\bar{E}^{s}\left(\Delta y_{t}\right)-\Delta y_{t} \mid \epsilon_{t}^{a}\right)$ & $0.56[0.39,0.76]$ & 0.53 & $\sigma\left(\bar{E}^{s}\left(\Delta y_{t}\right)-\Delta y_{t} \mid \epsilon_{t}^{b}\right)$ & $0.87[0.5,1.3]$ & 0.91 \\
\hline$\sigma\left(\bar{E}^{s}\left(\Delta y_{t}\right)-\Delta y_{t} \mid e_{t}^{a}\right)$ & $0.83[0.59,1.1]$ & 0.90 & $\sigma\left(\bar{E}^{s}\left(\Delta y_{t}\right)-\Delta y_{t} \mid e_{t}^{b}\right)$ & $0.98[0.55,1.3]$ & 0.87 \\
\hline$\sigma\left(\bar{E}^{s}\left(\pi_{t}\right)-\pi_{t} \mid \epsilon_{t}^{a}\right)$ & $0.35[0.24,0.53]$ & 0.46 & $\sigma\left(\bar{E}^{s}\left(\pi_{t}\right)-\pi_{t} \mid \epsilon_{t}^{b}\right)$ & $0.37[0.2,0.6]$ & 0.30 \\
\hline$\sigma\left(\bar{E}^{s}\left(\pi_{t}\right)-\pi_{t} \mid e_{t}^{a}\right)$ & $0.74[0.54,0.87]$ & 0.51 & $\sigma\left(\bar{E}^{s}\left(\pi_{t}\right)-\pi_{t} \mid e_{t}^{b}\right)$ & $0.36[0.24,0.49]$ & 0.22 \\
\hline
\end{tabular}

Note: The empirical moments matched in the estimation procedure are the median standard deviations computed from the successful IRFs of variables to shocks over the first five quarters. The values in square brakets corresponds to the 16 th and 84th percentile moments.

\subsubsection{The monetary policy channel}

The strength of the monetary policy channel depends on the persistence of demand shocks and on the monetary policy rule. Note first that the effect of demand noise shocks is larger when demand shocks are persistent. When this is the case, households not only face a current increase in interest rate, but also expect future interest rates to rise, which further depresses aggregate demand. This is illustrated in Fig. 5. The upper panel describes the model-based responses of output, inflation and nominal interest rate to demand noise shock in the benchmark calibration $\left(\rho_{b}=0.9\right)$ for two values of the Taylor rule parameter, that is, $\varphi=2$ (benchmark) and $\varphi=1.1$. The lower panel shows the associated responses when the demand shock is i.i.d. $\left(\rho_{b}=0\right)$. Comparing the upper and lower panels, we observe that demand noise shocks have a deeper impact when demand shocks are persistent.

Now consider the role of monetary policy. When demand shocks are i.i.d. (lower panel of Fig. 5), a more aggressive monetary policy $(\varphi=2)$ leads to a stronger recession because the current response of the interest rate is stronger. However, a more aggressive monetary policy mitigates the recession when demand shocks are persistent (upper panel). This is due to firms' expectations of future policy actions: When demand shocks are persistent and monetary policy aggressively fights inflation, firms (when receiving a positive signal on demand) expect that not only will the current interest rate increase, but also future interest rates, which deters them from increasing their prices and thus mitigates inflation. This triggers a lower equilibrium rise in interest rate, and the recession is milder. A strong policy response to inflation therefore paradoxically limits the amplification effect of monetary policy.

We check the validity of these implications by including the Federal Reserve Bank Funds rate in the SVAR model described in Section 3. Since we are interested in the monetary policy channel, we end the sample in 2008q2 so as to abstract from the period where the interest rate was at the zero lower bound. We also consider the Great Moderation sample (1983q2-2007q2), since it is often seen as a period where the Federal Reserve gained in credibility and managed to anchor private expectations by responding more aggressively to inflation (see, for instance, Clarida et al., 2000). Fig. 3 shows the response of real GDP, inflation and the Federal Reserve Bank Funds rate to demand noise shocks in these two samples. Consistent with the monetary policy channel, demand noise shocks generate a significant rise in the Federal Reserve Bank Funds rate in both samples, although the response is more delayed than in the model. In addition, interest rate, output and inflation react less to a demand noise shock during the Great Moderation period. This is consistent with monetary policy being more aggressive during that period than on average in our full sample.

\subsubsection{The firms' information paradox}

The contribution of noise shocks to output fluctuations depends on the structure of the economy and on policy, as we have just shown, but it also depends on the structure of information. Here, it is useful to compare information about demand with information about supply. Public signals about supply and demand have similar signal-to-noise ratios $\left(\left(\sigma_{a} / \sigma_{a 0}\right)^{2}=0.76\right.$ and $\left.\left(\sigma_{b} / \sigma_{b 0}\right)^{2}=1.33\right)$. Moreover, firms receive about as precise private signals about demand as households about supply $\left(\left(\sigma_{a} / \sigma_{a 1}^{c}\right)^{2}=0.86\right.$ and $\left.\left(\sigma_{b} / \sigma_{b 1}^{f}\right)^{2}=0.59\right)$. 

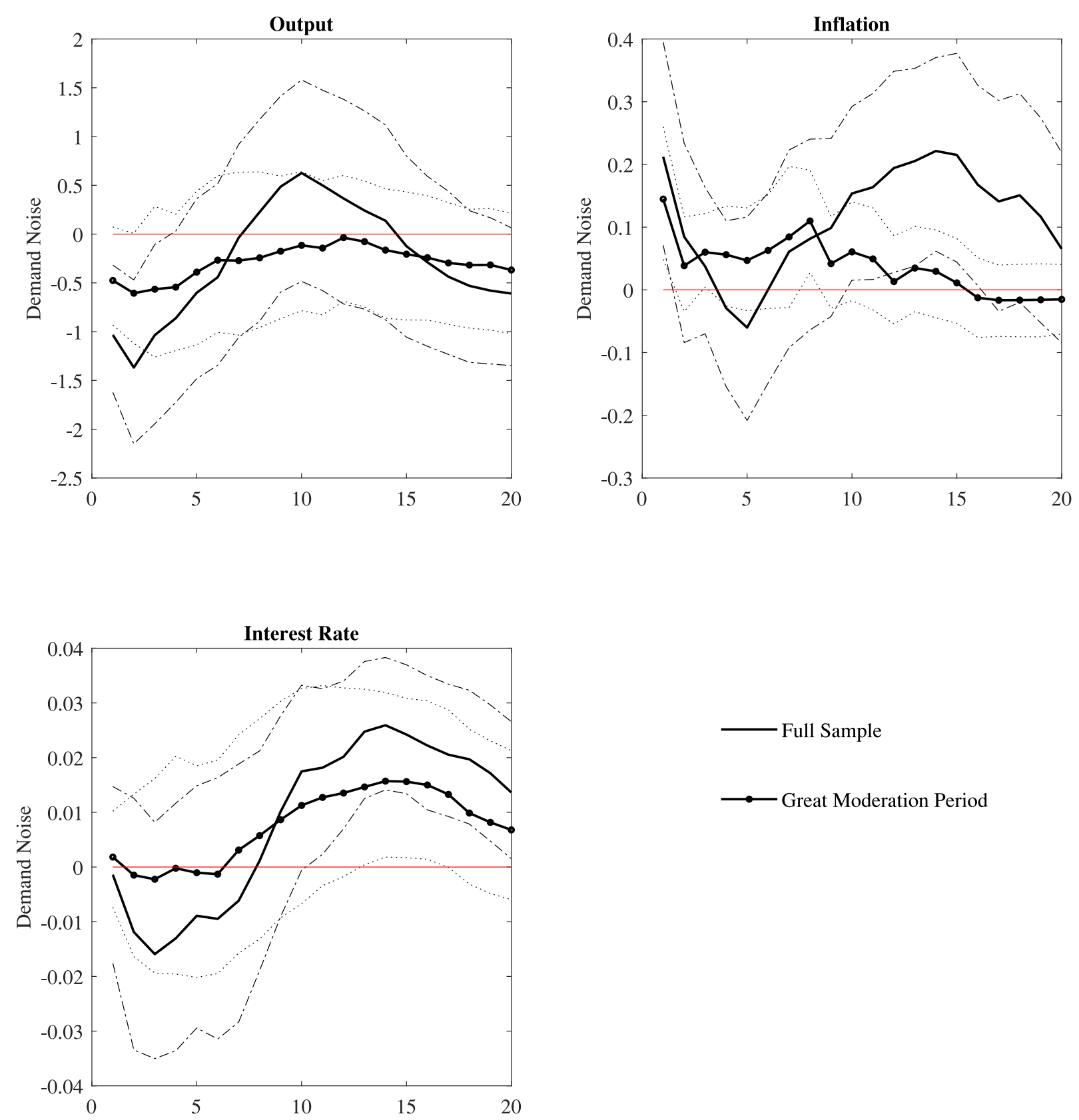

Fig. 3. IRfs to demand noise shocks - Role of the interest rate. Note: The solid line corresponds to the median of the responses in the SVAR model enlarged with the Fed Funds Rate over the sample 1969q2-2007q2. The dashed-dotted lines represent the 16th and 84th percentiles. The line with circles corresponds to the SVAR model enlarged with the Fed Funds Rate over the sample 1983q2-2007q2. The dotted lines represent the 16th and 84th percentiles.

We now explore how these estimates affect the contribution of noise shocks to output fluctuations. Fig. 4 shows the output volatility conditional on supply noise shocks as a function of $\sigma_{a 0}^{2}$ (left panel) and its volatility conditional on demand noise shocks as a function of $\sigma_{b 0}^{2}$ (right panel). The solid lines are for the benchmark estimation, while the dashed lines correspond to the case where private information is shut down $\left(\left(\sigma_{a 1}^{c}\right)^{-2}=0\right.$ in the left panel and $\left(\sigma_{b 1}^{f}\right)^{-2}=0$ in the right one). As expected, shutting down households' private information makes the conditional volatility of output to supply noise shocks larger. Indeed, when households do not have access to private information, a positive public signal makes them even more optimistic and leads them to increase their consumption even more. With demand noise shocks, the opposite happens. Shutting down firms' private information makes the conditional volatility of output to demand noise shocks smaller. This is what we call the firms' information paradox: Less information about demand generates less output volatility. This mitigated 

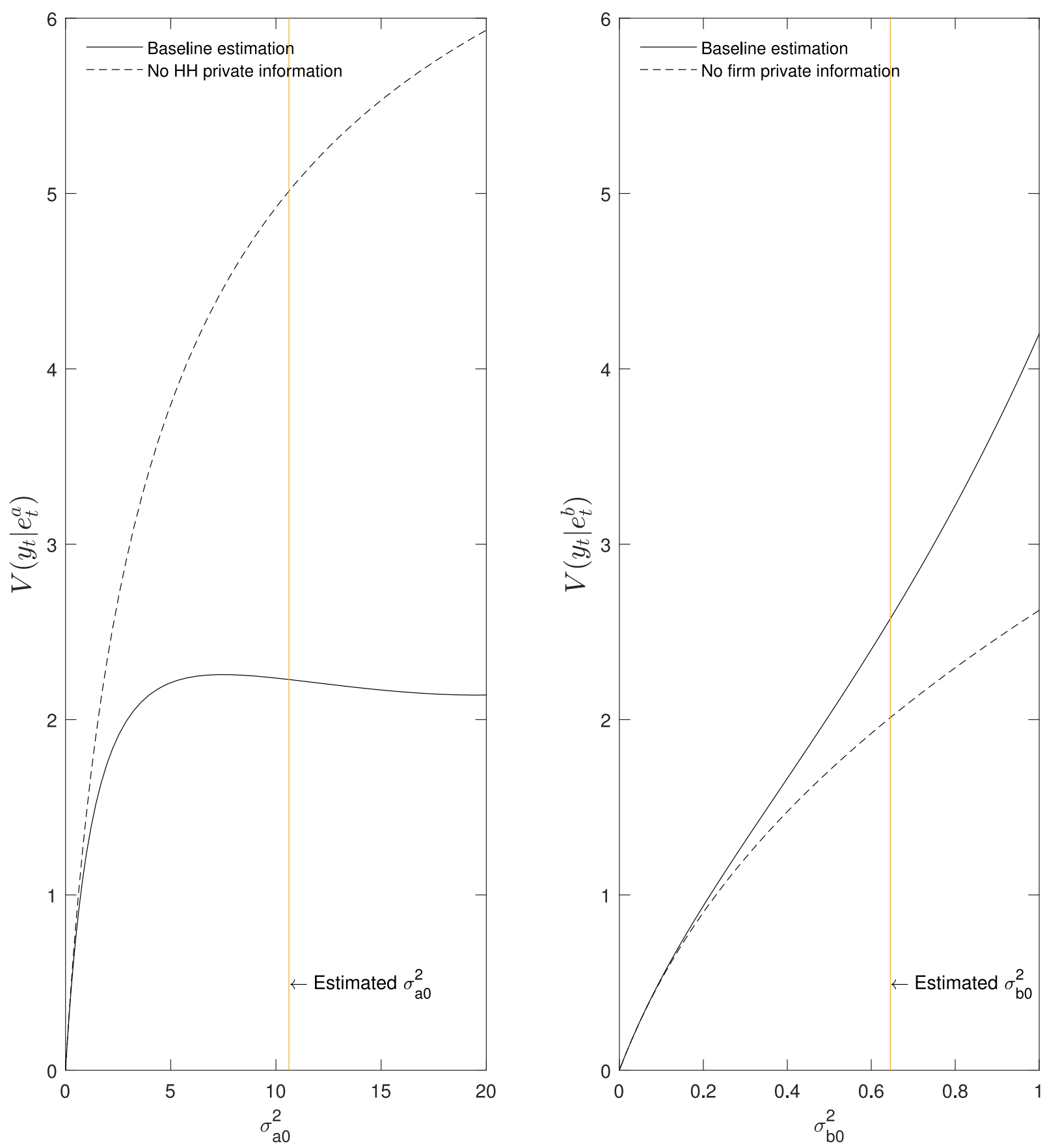

Fig. 4. Supply and demand noise - Role of information.

response of output actually results from an amplified response of inflation to demand noise shocks. Indeed, in the absence of private information, firms tend to be even more optimistic about demand when receiving a positive public signal. The demand noise shock is thus more inflationary, which mitigates the rise in the real interest rate and mitigates the response of output to demand noise shocks.

Note that, unsurprisingly, the variance of output conditional on supply noise is bounded as a function of $\sigma_{a 0}^{2}$, due to the decreasing weight households put on the public signal. This result is well known and has been highlighted by Lorenzoni (2009). However, this effect does not appear in the case of demand noise. Indeed, as $\sigma_{b 0}^{2}$ increases, the central bank becomes more and more uncertain about inflation, so demand noise shocks are more and more amplified because of the lack of monetary policy reaction. 

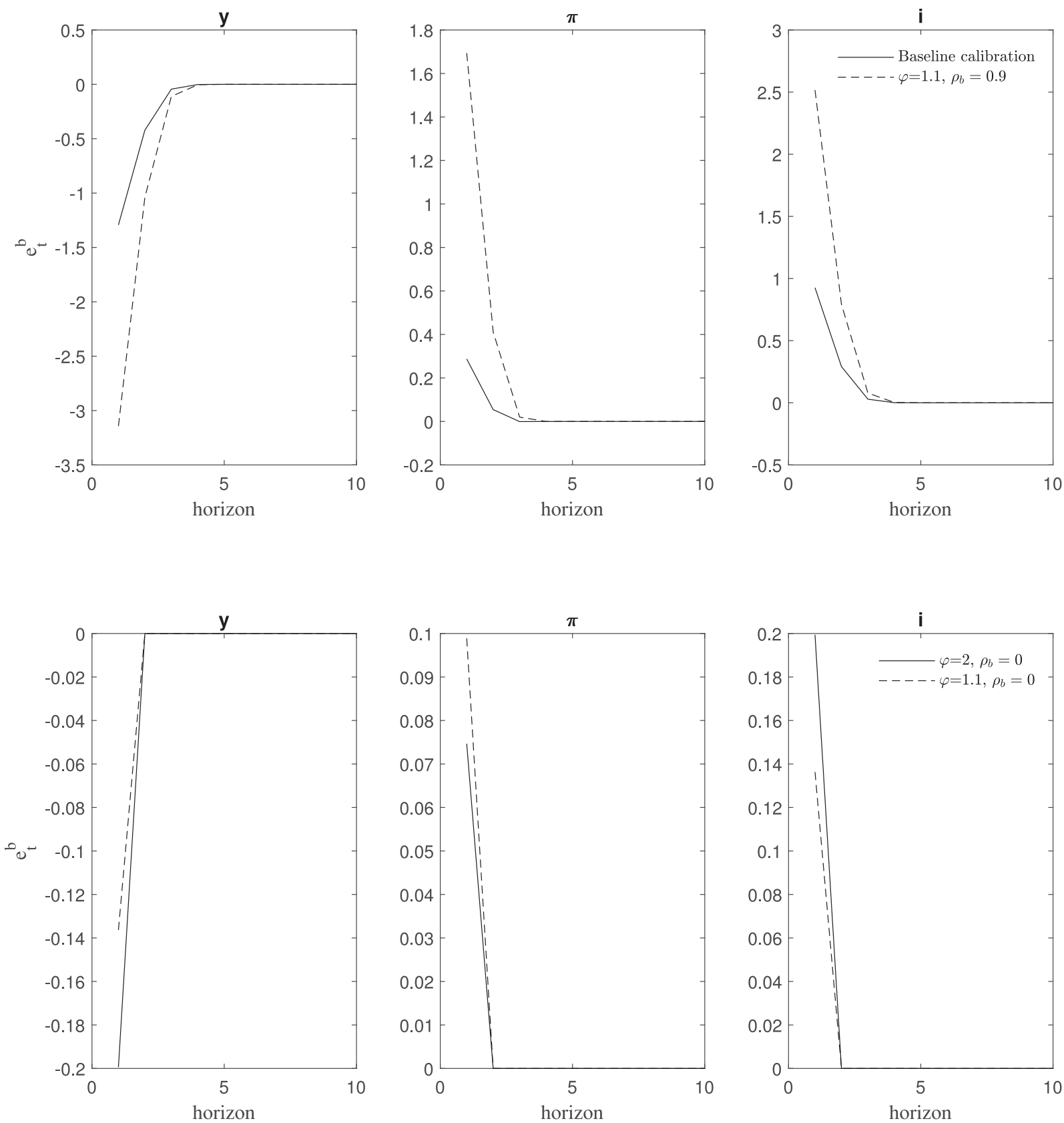

Fig. 5. Demand noise - role of monetary policy and persistence.

\section{Conclusion}

By using sign restrictions on SPF expectation errors about both output growth and inflation, we show that noise shocks, particularly demand noise shocks, contribute substantially to output fluctuations. Additionally, monetary policy seems to be a key determinant of the effect of demand noise shocks. However, a monetary policy rule that reacts more aggressively to inflation can reduce the effect of demand noise shocks. Finally, we highlight the fact that the amount of private information received by firms about demand contributes toward explaining the importance of demand noise shocks to fluctuations.

This study opens questions for future research. The central role that monetary policy seems to play in the transmission of noise shocks calls for further investigations of central banks' information. This line of research may help in designing optimal policies that are conditional on both private agents' and policy makers' imperfect information. 


\section{Acknowledgments}

We thank the anonymous referee as well as the associate editor Francesco Bianchi and the editor Yuriy Gorodnichenko for their helpful comments. We also thank Frédéric Martenet for his excellent research assistance and Philippe Andrade, Jess Benhabib, Beatriz de Blas, Fabrice Collard, Frédéric Dufourt, Stefano Eusepi, Patrick Fève, Gaetano Gaballo, Lucas Kyriacou, Baptiste Massenot, Leornado Melosi, Jean-Paul Renne, Mirko Wiederholt, Donghoon Yoo, the participants in the workshops and conferences Informational Frictions in Business Cycles (Villars), T2M (Paris), Empirical Macroeconomics (Gent, Belgium), Financial and Real Interdependencies (Marseille, France), New Approaches for Understanding Business Cycles (Mannheim), Macro workshop (Frankfurt), and the participants in seminars at the University of Lausanne, TSE, University of Alicante, Lyon-Lumière University, Louvain-la-Neuve University, Goethe University, the OFCE and Nuremberg University, the Bundesbank seminar series, for useful comments. This research was funded by an FNS research grant, Project \#100018_150068. This work was supported by French National Research Agency Grant ANR-17-EURE-0020.

\section{Supplementary material}

Supplementary material associated with this article can be found, in the online version, at doi:10.1016/j.jmoneco.2020. 01.006 .

\section{References}

Andrade, P., Crump, R., Eusepi, S., Emanuel, M., 2016. Fundamental disagreement. J. Monet. Econ. 83, 106-128.

Angeletos, G.-M., La'O, J., 2009. Incomplete information, higher-order beliefs, and price inertia. J. Monet. Econ. 56, 19-37.

Angeletos, G-M., La'o, J., 2013. Sentiments. Econometrica 81, 739-779.

Angeletos, G-M., Collard, F., Dellas, H., 2018. Quantifying confidence. Econometrica 86, 1689-1726.

Arias, J., Rubio-Ramírez, J.F., Waggoner, D., 2018. Inference based on SVARs identified with sign and zero restrictions: theory and applications. Econometrica $86,685-720$

Barsky, B., Sims, E.R., 2012. Information, animal spirits, and the meaning of innovations in consumer confidence. Am. Econ. Rev. 102, $1343-1377$.

Blanchard, J., L'Huillier, J.-P., Lorenzoni, G., 2013. News, noise, and fluctuations: an empirical exploration. Am. Econ. Rev. 103, 3045-3070.

Blanchard, J., Quah, D., 1989. The dynamic effects of aggregate demand and supply disturbances. Am. Econ. Rev. 79, 655-673.

Beaudry, P., Portier, F., 2004. An exploration into Pigou's theory of cycles. J. Monet. Econ. 51, 1183-1216.

Benhabib, J., Wang, P., Wen, Y., 2015. Sentiments and aggregate demand fluctuations. Econometrica 83, 549-585.

Chari, V.V., Kehoe, P.J., McGrattan, E.R., 2008. Are structural VARs with long-run restrictions useful in developing business cycle theory? J. Monet. Econ. 55, 1337-1352.

Chahrour, R., Ulbricht, R., 2019. Robust predictions for DSGE models with incomplete information. Mimeo.

Clarida, R., Galí, J., Gertler, M., 2000. Monetary policy rules and macroeconomic stability: evidence and some theory. Q. J. Econ. 115, 147-180.

Coibion, O., Gorodnichenko, Y., 2012. What can survey forecasts tell us about information rigidities? J. Polit. Econ. 120, 116-159.

Coibion, O., Gorodnichenko, Y., 2015. Information rigidity and the expectations formation process: a simple framework and new facts. Am. Econ. Rev. 105, $2644-2678$.

Coibion, O., Gorodnichenko, Y., Kamdar, R., 2018. The formation of expectations, inflation and the phillips curve. J. Econ. Lit. 56, $1447-1491$.

Croushore, D., 1993. Introducing: the survey of professional forecasters. Bus. Rev. (Nov.) 3-15.

Croushore, D., Stark, T., 2003. A real-time data set for macroeconomists: does the data vintage matter? Rev. Econ. Stat. 85, 605-617.

Dedola, L., Neri, S., 2007. What does a technology shock do? A VAR analysis with model-based sign restrictions. J. Monet. Econ. 54, 512-549.

Dees, S., Zimic, S., 2019. Animal spirits, fundamental factors and business cycle fluctuations. J. Macroecon. 61, 103-123.

Enders, Z., Kleemann, M., Müller, G., 2018. Growth expectations, undue optimism, and short-run fluctuations. Update of CESIfo Working Paper No. 4548.

Fève, P., Guay, A., 2019. Sentiments in SVARs. Econ. J. 129, 877-896.

Fève, P., Pietrunti, M., 2016. Noisy fiscal policy. Eur. Econ. Rev. 85, 144-164.

Forni, M., Gambetti, L., Lippi, M., Sala, L., 2017. Noisy news in business cycles. Am. Econ. J. 9, 122-152.

Francis, N., Ramey, V.A., 2006. The source of historical fluctuations: an analysis using long-run restrictions. In: Clarida, R., Frankel, J., Giavazzi, F., West, K. (Eds.), NBER International Seminar on Macroeconomics, 2004. The MIT Press, Cambridge, MA, pp. 17-49.

Galì, J., 2008. Monetary Policy, Inflation, and the Business Cycle: An Introduction to the New Keynesian Framework and Its Applications, second ed.

Gouriéroux, C., Monfort, A., Renault, E., 1993. Indirect inference. J. Appl. Econometr. 8, 85-118.

Guillermo, C., 1983. Staggered prices in a utility-maximizing framework. J. Monet. Econ. 12, 383-398.

Hamilton, J., 1995. Time Series Analysis. Princeton University Press.

Hürtgen, P., 2014. Consumer misperceptions, uncertain fundamentals, and the business cycle. J. Econ. Dyn. Control. 40, 279-292.

Jaimovich, N., Rebelo, S., Can news about the future drive the business cycle?Am. Econ. Rev. 99, 1097-1118.

Keynes, J.M., 1936. The general theory of employment. Interest Money.

Leeper, E., Walker, T.B., Yang, S.-C. S., 2013. Fiscal foresight and information flows. Econometrica 81, 1115-1145.

Lorenzoni, G., 2009. A theory of demand shocks. Am. Econ. Rev. 99, 2050-2084.

Melosi, L., 2014. Estimating models with dispersed information. Am. Econ. J. 6, 1-31.

Milani, F., 2017. Sentiments and the US business cycle. J. Econ. Dyn. Control 82, 289-311.

Nimark, K.P., 2014. Man-bites-dog business cycles. Am. Econ. Rev. 104, 2320-2367.

Pigou, A., 1926. Industrial Fluctuations. MacMillan, London.

Ricco, G., 2015. A New Identification of Fiscal Shocks Based on the Information Flow. ECB working paper 1813.

Uhlig, H., 2005. What are the effects of monetary policy on output? results from an agnostic identification procedure. J. Monet. Econ. 52, $381-419$.

Woodford, M., 2003. Imperfect common knowledge and the effects of monetary policy. In: Aghion, P., Frydman, R., Stiglitz, J., Woodford, M. (Eds.), Knowledge, Information, and Expectations in Modern Macroeconomics: In Honor of Edmund S. Phelps. Princeton University Press. 